\title{
25 Research Square \\ Psychological status and intervention strategy of maintenance hemodialysis patients in COVID-19 epidemic
}

\section{Jingwen Nie}

The First Affiliated Hospital of Kunming Medical University

\section{Shuang Zhu}

Kunming Tongren Hospital

\section{Wenlong Cui}

Kunming Medical University

\section{Huixin Wu}

Kunming Medical University

\section{Yaping Cai}

The First Affiliated Hospital of Kunming Medical University

\section{Xi Wen}

Dehong city Hospital of traditional Chinese Medicine

\section{Qing Li ( $\square$ liqing@kmmu.edu.cn )}

The First Affiliated Hospital of Kunming Medical University https://orcid.org/0000-0001-5452-2734

\section{Research article}

Keywords: novel coronavirus disease 2019; maintenance hemodialysis; post-traumatic stress disorder; psychologicalstatus

Posted Date: July 14th, 2020

DOI: https://doi.org/10.21203/rs.3.rs-38725/v1

License: (a) (1) This work is licensed under a Creative Commons Attribution 4.0 International License. Read Full License 


\section{Abstract}

Background An outbreak of novel coronavirus disease 2019 (COVID-19) is a newly discovered contagious disease, which first broke out in China.Based on the psychological state, maintenance hemodialysis (MHD) patients might bear psychological problemsunder the COVID-19epidemic situation.To evaluate the psychological health of MHDpatients and explore the corresponding intervention strategies.

Methods Acluster sampling approach was employed to obtain a sample of 206 MHD patients from two hospitals in Yunnan province: a COVID-19-designated hospital and a non-COVID-19-designated hospital. Post-traumatic stress disorder (PTSD) checklistwas used to assess the psychological status, while Kidney Diseaseand Quality of Life -Short Form(KDQOL-SF)was applied to assess the quality of life(QOL). The factorsinfluencing thepsychological status in MHD patients were employed by binary logistic regression.

Results Among MHD participants (age $53.4 \pm 15.3$ years), 61 cases showed mild to moderate positive PTSD, and 72 casespresented severe positive PTSD.The level of education, capital income, hospital, depressive tendency, and QOL were the influence factors for the occurrence of PTSD. Moreover, the PTSD was negatively correlated with QOL and positively correlated with COVID-19-designated hospital and the depressive tendency.

Conclusion During the COVID-19 epidemic, MHD patients, especially in COVID-19-designated hospitals, with low QOL and depressive tendency had a high incidence of positive PTSD, which requires prompt psychological counseling and effective measures from medical staff to ensure timely treatment of patients.

\section{Background}

In late 2019, an outbreak of novel coronavirus disease 2019 (COVID-19) is a newly discovered contagious disease caused by SARS-CoV-2 virus, which first broke out in China, primarily manifesting as severe respiratory illness and human-to-human transmission, but can affect multiple organs, such as kidney, digestive tract, heart, and blood system.It is rapidly spreading worldwide has raised global concerns [1, 2]. After 7 months, we are still experiencing a devastating pandemic with local outbreaks across all continents. By the end of June 2020, the World Health Organization (WHO) reported more than $10,000,000$ confirmed COVID-19 cases and 500,000 deaths across 210 countriesand regions. The infection has developed into a world emerging health threat [3].

In order to contain the spread of this disease, scientists from various countries have focused their efforts on the study of its epidemiology, clinical features, modes of transmission, and the management of COVID-19. Although with the advanced medical science and resources, the impact on the public was direct and realistic with prolonged duration and wide coverage; also, it might cause a series of psychological problems [4]. 
Reportedly, viral RNA has been identified in both kidney tissue and urine; moreover, infectious SARS-CoV-2 was successfully isolated from semen and urine of a COVID-19 patient [5]. Also, maintenance hemodialysis (MHD) patients developed COVID-19 infection in hemodialysis (HD) centers [6-8]. An HD center is the unit with concentrated population and high mobility. MHD patients need to go to the HD centers for HD 3 times a week for $4 \mathrm{~h}$ each time. During the frequent trips between the HD center and home, the risk of COVID-19 infection could be high. Moreover, these patients are accompanied by various complications [9]. Based on the psychological state, MHD patients might bear more psychological problemsunder the epidemic situation than the normal population.

Thus, the present study evaluated the psychological health level of MHD patients under the COVID-19 epidemic situation in order to provide emergency psychological intervention strategies.

\section{Methods}

\section{Study area, population, and sampling techniques}

A cross-sectional survey was conducted in May 2020. Acluster sampling approach was employed to extract a sample of 206 MHD patients. The COVID-19-designated hospitalisresponsible for unified screening of suspected COVID-19 patients and treating confirmed COVID-19 patients, whilethe nonCOVID-19-designated hospitalis not responsible for screening and treating COVID-19 patients. The First Affiliated Hospital of Kunming Medical University is the COVID-19-designated hospital, whileKunming TongrenHospital is thenon-COVID-19-designated hospital. The inclusion criteria were as follows: patient'sglomerular filtration rate $<15 \mathrm{~mL} / \mathrm{min} .1 .73 \mathrm{~m}^{2}$; receive $\mathrm{HD}$ three times/week for $4 \mathrm{~h}$ each time over a period longer than 3 months; aged $\geq 18$ years. The exclusion criteria were as follows: the induction period of hemodialysis, recent major surgery,dottiness, malignant tumors, and patients who were unwilling to cooperate.

\section{Measuring tools}

Post-traumatic stress disorder (PTSD) is a psychological disorder characterized by intense fear, helplessness, and avoidance, resulting from exposure to a traumatic event or catastrophic life event. It is clinically manifested with three main syndromes: re-experiencing, avoidance behavior or numbness, and physiological hyperarousal $[10,11]$. The current study used the post-traumatic checklist scale (PCLS-L) to measure the PTSD of MHD patients. PCLS-L is a brief and self-report questionnaire for evaluating the severity of three main syndromes inPTSD [12]. It encompasses a wide variety of three projects, which is divided into 17 items, such as items 1-5 (re-experiencing), items 6-12 (avoidance), and items 13-17 (hyperarousalsyndrome).Each itemwas subjected to five-level scoring to accumulate the total score. The range of scores was 17-85; the higher score implied the higher likelihood of suffering PTSD. Normal: the total score is 17-37; mild and moderatePTSD: $38-49$; severe of PTSD: $50-85$ [13, 14].

Kidney Disease and Quality of Life-Short Form (KDQOL-SF) can be defined as a kidney patient's usual or 
survey (SF36) and kidney disease target areas (KDTAs). It is a comprehensive assessment of general health status and kidneydisease-related clinical characteristics[15].KDQOL-SF is an overall assessment of QOL in MHD patients.

\section{Data collection}

Four doctors and two medical students were educated as interviewers for data collection. The questionnaire included demographic characteristics, the age of onset, complications, the duration of treatment, transportation, educational level, income, PCLS-L,and KDQOL-SFTM. The capital income was adjusted to 2020 values and converted to USD using the official conversion rate in2020 ( $\$ 1.00=¥ 7.13)$.

\section{Statistical Analysis}

SPSS 23.0 software was used for statistical analysis. The enumeration data were expressed as percentages. The quantitative data between two groups were expressed as mean \pm standard deviation, while the affecting factors ofPTSD wereanalyzed bybinary logistics regression analysis. Statistical significance was based on two-tailed P-values, and a P-value of $<0.05$ was considered to be statistically significant.

\section{Results}

A total of 215 MHD participants from two HD centers,one is COVID-19-designated hospital, and the other is a non-COVID-19-designated hospital. Of these, 206 consented, representing a response rate of $95.8 \%$. Consequently, a total of 206 valid questionnaires were collected.

\section{General characteristics of the patients}

A total of 206 MHD participants, aged $\geq 18$ years, underwent MHD, $4 \mathrm{~h} /$ session, three times/week. The general characteristics of the patients are presented in Table 1. The cohort consisted of 128 males and 78 females; the ratio of male to female was 1.64 , and the average age was $53.4 \pm 15.3$ (range: 18-90)years-old. About $69 \%$ of the MHD participants were from COVID-19-designated hospitals. The patients in the COVID-19-designated hospital had a higher level of education and capital income than patients in the non-COVID-19-designated hospital group $(P<0.05)$. Moreover, the patients in COVID-19-designated hospital were younger, while the duration of HD in the non-COVID-19-designated hospital was longer $(\mathrm{P}<$ 0.01). 
Table 1

Demographic characteristics of the study population

\begin{tabular}{|llll|}
\hline Characteristics & $\begin{array}{l}\text { COVID-19-designated } \\
\text { hospital }\end{array}$ & $\begin{array}{l}\text { Non-COVID-19-designated } \\
\text { hospital }\end{array}$ & Total \\
\hline Age, mean (SD) & $52.0(15.1)$ & $56.4(15.5)$ & $53.4(15.3)$ \\
\hline$<60$ years (\%) & $101(71.1)$ & $37(57.8)$ & $138(67.0)$ \\
$\geq 60$ years (\%) & $41(28.9)$ & $27(42.2)$ & $68(33.0)$ \\
\hline Gender & & & $128(62.1)$ \\
\hline Male(\%) & $85(59.9)$ & $43(67.2)$ & $78(37.9)$ \\
\hline Female(\%) & $57(40.1)$ & $21(32.8)$ & $51.4 \pm 80.8$ \\
\hline $\begin{array}{l}\text { Duration of dialysis } \\
\text { (months) ** }\end{array}$ & $38.1 \pm 61.4$ & $80.9 \pm 107.2$ & $84(40.8)$ \\
\hline Level of education** & & & $51(24.8)$ \\
\hline Primary or lower (\%) & $44(31.0)$ & $40(62.5)$ & $71(34.5)$ \\
\hline High school (\%) & $39(27.5)$ & $12(18.8)$ & $7439.96 \pm$ \\
\hline University or higher (\%) & $59(41.5)$ & $12(18.8)$ & 5147.95 \\
\hline Capital income (USD)* & $8012.01 \pm 5127.31$ & $6030.28 \pm 4966.60$ & \\
\hline$* * P<0.01, * P<0.05$ & & & \\
\hline
\end{tabular}

\section{PCLS-L in MHD patients}

Several studies have suggested that a score of 38 is the critical value in the PCLS-L for PTSD-positive patients $[16,17]$. Therefore, the score of $\geq 38$ points was classified as positive PTSD in this study. The higher score implied the higher likelihood of suffering from PTSD, which encompasses a wide variety of three projects: re-experiencing, avoidance, and hyperarousal. In this study, the average PCLS-L score was $42.55 \pm 14.51$ (range: $27-59$ ). A total of 61 cases showed mild to moderate positive PTSD $(29.6 \%)$ and 72 cases were severe PTCD (35.0\%). Table 2 shows the scores of different dimensions among the three projects in PCLS-L. Participants with higher education level had higher scores of PCLS-L $(P<0.05)$. In addition, MHD patients with higher capital income had higher scores of PCLS-L $(P<0.01)$. Conversely, the scores of MHD patients in the non-COVID-19-designated hospital were lower than those in the COVID-19designated hospital $(P<0.01)$. Also, the scores of patients with depressive tendencies were higher than those without such tendencies $(P<0.01)$. 
Table 2

Dimensional scores of PCLS-L $(x \pm S)$

\begin{tabular}{|c|c|c|c|c|}
\hline \multirow[t]{2}{*}{ Variables } & \multicolumn{4}{|l|}{ PCLS-C } \\
\hline & Reexperiencing & Avoidance & Hyperarousal & Total \\
\hline \multicolumn{5}{|l|}{ Age } \\
\hline$<60$ years & $13.03 \pm 4.78$ & $17.28 \pm 6.09$ & $12.47 \pm 4.31$ & $\begin{array}{l}42.78 \pm \\
14.34\end{array}$ \\
\hline$\geq 60$ years & $12.74 \pm 5.25$ & $16.90 \pm 6.38$ & $12.46 \pm 4.60$ & $\begin{array}{l}42.09 \pm \\
14.95\end{array}$ \\
\hline \multicolumn{5}{|l|}{ Gender } \\
\hline Male & $12.50 \pm 5.07$ & $16.66 \pm 6.23$ & $12.27 \pm 4.45$ & $\begin{array}{l}41.42 \pm \\
14.70\end{array}$ \\
\hline Female & $13.64 \pm 4.63$ & $17.96 \pm 6.04$ & $12.79 \pm 4.32$ & $\begin{array}{l}44.40 \pm \\
14.09\end{array}$ \\
\hline \multicolumn{5}{|l|}{ Level of education } \\
\hline Primary or lower & $11.65 \pm 5.06^{\star \star}$ & $\begin{array}{l}15.80 \pm \\
5.90^{\star}\end{array}$ & $11.61 \pm 4.21$ * & $\begin{array}{l}39.06 \pm \\
14.17^{\star}\end{array}$ \\
\hline High school & $13.73 \pm 4.50$ & $17.69 \pm 5.80$ & $12.55 \pm 4.33$ & $\begin{array}{l}43.96 \pm \\
13.63\end{array}$ \\
\hline University or higher & $13.87 \pm 4.79$ & $18.37 \pm 6.52$ & $13.42 \pm 4.52$ & $\begin{array}{l}45.66 \pm \\
14.83\end{array}$ \\
\hline \multicolumn{5}{|l|}{ Capital income (USD)** } \\
\hline$\leq 3086$ & $10.80 \pm 4.08$ & $13.82 \pm 4.27$ & $10.73 \pm 3.54$ & $\begin{array}{l}35.35 \pm \\
10.17\end{array}$ \\
\hline$>3086$ & $13.81 \pm 4.99$ & $18.52 \pm 6.33$ & $13.18 \pm 4.53$ & $\begin{array}{l}45.51 \pm \\
15.01\end{array}$ \\
\hline \multicolumn{5}{|l|}{ Hospital** } \\
\hline COVID - 19-designated hospital & $15.48 \pm 3.54$ & $19.80 \pm 5.18$ & $14.18 \pm 3.84$ & $\begin{array}{l}49.45 \pm \\
11.29\end{array}$ \\
\hline $\begin{array}{l}\text { Non-COVID - 19-designated } \\
\text { hospital }\end{array}$ & $7.28 \pm 1.98$ & $11.28 \pm 3.65$ & $8.67 \pm 2.95$ & $27.23 \pm 7.36$ \\
\hline \multicolumn{5}{|l|}{ Modes of trip } \\
\hline Public transport & $13.57 \pm 4.82$ & $18.25 \pm 6.13$ & $13.22 \pm 4.38$ & $\begin{array}{l}45.04 \pm \\
14.36\end{array}$ \\
\hline
\end{tabular}




\begin{tabular}{|lllll|}
\hline Variables & \multicolumn{2}{l}{ PCLS-C } & & \\
\cline { 2 - 5 } & Reexperiencing & Avoidance & Hyperarousal & Total \\
\hline Personal motor vehicle travel & $12.56 \pm 4.97$ & $16.51 \pm 6.13$ & $12.02 \pm 4.36$ & $41.09 \pm$ \\
\hline Depressive tendency** & & & & 14.46 \\
\hline Yes & & & & \\
\hline No & $15.51 \pm 3.96$ & $20.60 \pm 4.93$ & $14.95 \pm 3.72$ & $51.60 \pm$ \\
\hline Total & & & & 11.21 \\
\hline *P<0.05, **P<0.01 & $10.50 \pm 4.53$ & $13.90 \pm 5.45$ & $10.10 \pm 3.65$ & $34.50 \pm$ \\
\hline
\end{tabular}

\section{Influencing factors of PTSD}

Binary logistics regression was performed with PCLS-L of MHD patients. The dependent variable is the positive PTSD ( 0 = asymptomatic, $1=$ symptomatic), while age $(0=$ less than 60 years, $1=$ exceed 60 years), level of education ( 0 = below junior school, $1=$ high school, $2=$ bachelor's degree or above), gender $(0=$ male, $1=$ female $)$, per capita income $(0=$ less than $\$ 3086,1=$ more than $\$ 3086)$, hospital $(0=$ COVID-19-designated hospital, $1=$ non-COVID-19-designated hospital), mode of trip ( $0=$ public transport, 1 = personal motor vehicle $)$, duration of treatment ( 0 = less than 12 months, $1=$ exceed 12 months $)$, and depressive tendency $(0=$ no, $1=$ yes) were independent variables (Table 3$)$. The present study revealed that the factors affecting the PCLS-L included hospital $(B=4.331, P<0.001)$, depressive tendency $(B=$ $1.639, \mathrm{P}<0.05)$, and KDQOL-SF $(B=0.076, \mathrm{P}<0.05)$. The PTSD was positively correlated with COVID-19designated hospital and depressive tendency but negatively correlated with KDQOL-SF. 
Table 3

Influencing factors of PCLS-L in MHD patients

\begin{tabular}{|llllll|}
\hline Variables & B & Standard Error & OddsRatio & $95 \%$ confidence interval & P \\
\hline Age & -0.421 & 0.618 & 0.656 & $(0.195,2.205)$ & 0.496 \\
\hline Level of education & -0.261 & 0.393 & 0.770 & $(0.357,1.663)$ & 0.506 \\
\hline gender & -0.305 & 0.544 & 1.357 & $(0.467,3.941)$ & 0.575 \\
\hline Capital income & -0.080 & 0.588 & 0.923 & $(0.292,2.922)$ & 0.892 \\
\hline Hospital & 4.331 & 0.664 & 0.013 & $(0.004,0.048)$ & 0.000 \\
\hline Modes of trip & -0.099 & 0.598 & 0.906 & $(0.280,2.926)$ & 0.868 \\
\hline Durationof treatment & -0.033 & 0.539 & 0.968 & $(0.336,2.784)$ & 0.952 \\
\hline Depressive tendency & 1.639 & 0.646 & 5.152 & $(1.452,18.280)$ & 0.011 \\
\hline KDQOL-SF & 0.076 & 0.034 & 1.079 & $(1.009,1.155)$ & 0.026 \\
\hline
\end{tabular}

\section{Discussion}

The outbreak of COVID-19 is a rare pandemic. The closing of schools, businesses, sporting events, and meetings is a critical element in "social distancing," a powerful tool to restrict transmission of this disease [18]. Such unprecedented steps create anxiety and uncertainty in humans that is unparalleled in modern history. MHD patients who experience the COVID-19 epidemic situationare vulnerable to emotional pain and other difficulties [19]. The current study quantitatively examined the psychological characteristics of HD patients' experiences during this epidemic in addition to the influencing factors of PTSD.

\section{Probable causes of psychological crisis in MHD patients in the COVID-19epidemic}

MHD patients constitute a distinct and high-risk group [20], which is often associated with low immunity, decline or even loss the ability of work, substantial economic burden, inability to fulfill family responsibilities and participate in active social life, and suffer from various complications such as, muscle weakness, pruritus, fatigue, diabetic, hypertension, and restless legs. These factors are associated with lower QOL and poor clinical outcomes, leading to a higher risk of psychological crisis in MHD patients than that in the general population [21, 22].

Due to the characteristics of novelty, asymptomatic shedding, long incubation period, COVID-19 can be directly transmitted from person to person, spreading rapidly and exhibiting variable manifestations; thus, the outbreak of COVID-19 is a challenge to the existing health systems [23, 24].To date, specific treatment and prevention options, such as targeted antiviral drugs and vaccines, are not available [25]. Hence, the MIபn manmmandad traditinnal nuwlin honlth nuthmal maponse tactics-quarantine, isolation, social Loading [MathJax]/jax/output/CommonHTML/fonts/TeX/fontdata.js 
distancing, and community containment [26]. However, in order to obtain hemodialysis, MHD patients need to travel from home to the HD center three times each week for $4 \mathrm{~h} /$ session, serving as potential vectors for infection. This same shift of MHD patients should be set in the same closed space in a HD unit, and thus, home isolation cannot be realized. In thisstudy, the risk of PTSD occurrence in COVID-19 designated hospital is higher than that in the non-COVID-19 designated hospital, indicating that MHD patients in COVID-19 designated hospitals were facing more serious psychological stress and more anxious mental health conditions. Moreover, due to the specificity of the HD center, i.e., donning biohazard suits by medical staff managing patients and inquiry into the history of exposure and clinical symptoms, by each shift, which will inevitably bring about strong fear and aggravate the psychological harm in MHD patients [27].

Indubitably, a myriad of incorrect and false information is spread on the Internet. Many citizens express their negative emotions such as anxiety, fear, worry, and tension, through social media, and hence, excessive mass media exposure, including the latest updated epidemic reports, the number of confirmed cases, and increasing death-toll lead to the "information epidemic." The spreading of rumors and difficulty in obtaining trustworthy information further aggravates the anxiety and fear of MHD patients. During the dialysis interphase, the MHD patients were isolated at home, resulting in less contact with the outside world, which increased the feelings of loneliness and helplessness, in turn increasing the risk of psychological crisis.

\section{Intervention tactics}

Despite the introduction of the psychological first aid manual (PFA) by the WHO in 2005, there has been a lack of psychological support and counseling model based on local cultural characteristics pertaining to MHD. Thus, the management of MHD patients under the COVID-19 pandemic needs to be under intensive focus, especially the MHD patients in COVID-19 designated hospitals who exhibit depressive tendencies.

Firstly, the COVID-19-related and mental health education of MHD patients is strengthened using bulletin board, phone Application, official accountsof WeChat, improving the scientific understanding of the outbreak, and ensuring that every patient (or families/carers) focuses on the official accounts of HD center and join the WeChat group of HD center. The WeChat group and official accounts may provide mental health knowledge and COVID-19-related protection information regularly. For example, the questionnaire survey revealed that few patients know diarrhea as one of the symptoms of COVID-19 [28], but have a poor understanding of the correct disinfection methods at home; the education with respect to such situation is strengthened via WeChat.

Secondly, effective psychological monitoring should be carried out by medical teams, especially in COVID-19 designated hospitals. The medical staff in COVID-19 designated hospitals should recognize that adjustment and intervention measuresfor mental disorders should be initiated as early as possible. The psychological evaluation form and questionnaire identified the high-risk patients who were then selected for interviews. Targeted professional psychological support was provided by psychological 
addition, the medical staff of the HD unit should provide appropriate humane care to enhance the sense of belonging and social support in MHD patients [29].

Finally, if medical conditions permit, the ventilation and alexipharmic environment should be recommended in the HD unit. The access control system and epidemic buffer zone should be set up, attaining the pre-examination in batches to reduce the aggregation of patients, thereby creating a comfortable, clean, and relaxed environment in the HD unit. During the dialysis interphase, the patients' communication with family members should be increased, such as perform chores and enjoy entertainment together, which would reduce negative emotions, maintain a balanced diet, and gain adequate sleep. Therefore, an optimistic and healthystate of mind is created.

\section{Conclusions}

COVID-19 poses a severe threat to the mental health of both medical staff and MHD patients. MHD patients with low QOL,depressive tendency, and in COVID-19-designated hospital,have a high incidence of positive PTSD. Early detection of mental problems and interventions are crucial. Medical staff, MHD patients, and their families work together to establish the corresponding intervention strategies.

\section{Limitations}

The present study has some limitations. First, it is a cross-sectional study, and hence, prospective researches with large samples should be employed to further confirm the conclusions. Secondly, this is the first outbreak of COVID-19, lacking baseline data. Finally, due to financial constraints, only a few indicators were applied for the survey of psychological status, which should be improved in future studies.

\section{Abbreviations}

MHD- Maintenance hemodialysis

COVID-19- Novel coronavirus disease 2019

PCLS-LPost- traumatic stress disorder checklist-specific

PTSD- Post-traumatic stress disorder

KDQOL--SF- Kidney Disease andQuality of LifeShort Form

HD- Hemodialysis

WHO- World Health Organization

\section{Declarations}


Ethics approval and consent to participate:The study was conducted in accordance with the Declaration of Helsinki, and the Ethics Committee of Kunming Medical University approved the protocol. All participantshavegiven written informed consent.

Consent for publication:Not applicable.

Availability of data and materials:The datasets used and/or analysed during the current study are available from the corresponding author on reasonable request.we confirm that the data on the sample of 206 MHD patients from two hospitals have not been reported in any other submission by us or anyone else.

Competing interests:The authors declare that there are no conflicts of interest.

Funding:This study was supported by grants from "the Union Specific Project Foundation of Yunnan Provincial Science and Technology Department and Kunming Medical University"[2017FE467(-037)] , the "Teaching Educational Reform Project of Kunming Medical University"(2018-JY-Y-050), the "Project of one undred of young and middle-aged academic and technical talent in Kunming Medical University(60118260103) " and "Project of medical talents training in Yunnan Health Committee区H2018052 『".

Authors' contributions: QL conceived the idea, designed the study, administered theproject, and drafted on the manuscript. JN conducted the field study and drafted the original manuscript. SZ conducted field study and investigation. WC conducted theinvestigationand curated the data. YCcollected the data. HW provided critical comments and edited the manuscript. XW conducted theinvestigation. All authors approved the final version of the manuscript.

Acknowledgements $\square$ We would like to thank Dr Zhu Zhou , and Dr Ming Guofor invaluable practical assistance.

\section{References}

1. Zhu N, Zhang D, Wang W, Li X, Yang B, Song J. A Novel Coronavirus from Patients with Pneumonia in China, 2019. N Engl J Med.2020; 382(8):727-733. https:// doi.org/ 10. 1056/ NEJMoa 2001017.

2. $10.1001 /$

Wu Z, McGoogan JM.Characteristics of and Important Lessons From the Coronavirus Disease 2019 (COVID-19) Outbreak in China: Summary of a Report of 72314 Cases From the Chinese Center for Disease Control and Prevention. JAMA. 2020 https://doi.org/ 10.1001/ jama. 2020. 2648.

3. World Health Organization. Coronavirus disease 2019 (COVID-19): situation report 44. Published Mar 4. 2020. https://www. who. int/docs/ default-source/ coronaviruse/ situation-reports/ 2020 0304sitrep44-covid-19.pdf?sfvrsn = 783b4c9d_2.

4. Li Z, Ge J, Yang M, Yang C.Vicarious traumatization: A psychological problem that cannot be ignored Loading [MathJax]/jax/output/CommonHTML/fonts/TeX/fontdata.js 2020.https://doi.org/ 10.1016/ 
j.bbi.2020.04.047.

5. https://doi.org 10.1080/

Sun J, Zhu A, Li H, Li YM. Isolation of Infectious SARS-CoV-2 from Urine of a COVID-19 Patient.Emerg Microbes Infect.2020;9(1):991-93.28:1-8. https://doi.org 10.1080/ 22221751. 2020. 1760144.

6. content/10.1101/2020.02.24.20027201v2

Ma Y, Diao B, Lv X, ZhuL, Liang W. 2019 novel coronavirus disease in hemodialysis (HD) patients: Report from one HD center in Wuhan, China.2020; Available at https:// www.medrxiv.org/ content/10.1101/2020.02.24.20027201v2. Accessed 2020 Mar 02.

7. Wang R, Liao C, He H, Shui H. COVID-19 in Hemodialysis Patients: A Report of 5 Cases. Am J Kidney Dis. 2020.https://doi.org10.1053/j.ajkd.2020.03.009.

8. Ferrey AJ, ChoiG, Hanna RM, Kalantar-Zadeh KA. Case of Novel Coronavirus Disease 19 in a Chronic Hemodialysis Patient Presenting with Gastroenteritis and Developing Severe Pulmonary Disease.Am J Nephrol.2020;51(5):337-42. https://doi.org 10.1159/000507417.

9. El Shamy O, Tran H, Sharma S, Uribarri J.Telenephrology with Remote Peritoneal Dialysis Monitoring during Coronavirus Disease 19. Am J Nephrol.2020.1-3. https://doi.org/ 10.1159/ 000508023.

10. Zuromski KL, Ustun B, Hwang I, Kessler RC. Developing an optimal short-form of the PTSD Checklist for DSM-5 (PCL-5).Depress Anxiety.2019. 36(9):790-800. https://doi.org/10.1002/da.22942.

11. Yue JK, Levin HS, Suen CG, Investigators TRACK-TBI. Age and sex-mediated differences in six-month outcomes after mild traumatic brain injury in young adults: a TRACK-TBI study. Neurol Res. 2019;41(7):609-23. https://doi.org/10.1080/01616412.2019.1602312.

12. Adhikari Baral I, K C B. Post traumatic stress disorder and coping strategies among adult survivors of earthquake, Nepal BMC Psychiatry.2019;19(1):118. https://doi.org/ 10.1186/s12888-019-2090-y.

13. Zuromski KL, Ustun B, Hwang I, Kessler RC. Developing an optimal short-form of the PTSD Checklist for DSM-5 (PCL-5). Depress Anxiety. 2019;36(9):790-800. https://doi.org/ 10.1002/da.22942.

14. Alhalal E, Ford-Gilboe M, Wong C, AlBuhairan F.Reliability and validity of the Arabic PTSD Checklist Civilian Version (PCL-C) in women survivors of intimate partner violence. Res Nurs Health. 2017;40(6):575-85. https://doi.org/ 10.1002/nur.21837.

15. Patil PP, Pawar S. ThakurdesaiP. Translation and Validation of Kidney Disease and Quality of Life (Kdqol-Sftm 1.2) Instrument to Measure Health Related Quality of Life Of Indian Patients with Kidney Disease. Value Health.2014; 17(7):A813. https://doi.org/ 10.1016/j.jval.2014.08.563.

16. Dobie DJ, Kivlahan DR, Maynard C, Bradley KA. Screening for post-traumatic stress disorder in female Veteran's Affairs patients: validation of the PTSD checklist. Gen Hosp Psychiatry. 2002;24(6):367-74. https://doi.org 10.1016/s0163-8343(02)00207-4.

17. Geier TJ, Hunt JC, Nelson LD, deRoon-Cassini TA. Detecting PTSD in a traumatically injured population: The diagnostic utility of the PTSD Checklist for DSM-5.Depress Anxiety. 2019;36 (2):170-178. https://doi.org10.1002/da.22873.

18. Guan WJ, Ni ZY, Hu Y. China Medical Treatment Expert Group for Covid- 9.Clinical Characteristics of Loading [MathJax]/jax/output/CommonHTML/fonts/TeX/fontdata.js 20;382(18):1708-20. https: //doi.org 
10.1056/NEJMoa2002032.

19. Arentz M, Yim E, Klaff L, Lokhandwala S, Riedo FX, Chong M.Characteristics and Outcomes of 21 Critically III Patients With COVID-19 in Washington State. JAMA.2020; Epub ahead of print.https://doi.org/10.1001/jama.2020.4326.

20. Huixin W, Qing L, Yap C. Economic burden and cost-utility analysis of three renal replacement therapies in ESRD patients from Yunnan Province. China IntUrol Nephrol. 2020;52(3):573-9. https://doi.org/10.1007/s11255-020-02394-1.

21. Mehrotra R, Cukor D, Unruh M, Hedayati SS. Comparative Efficacy of Therapies for Treatment of Depression for Patients Undergoing Maintenance Hemodialysis: A Randomized Clinical Trial. Ann Intern Med. 2019;170(6):369-379. https://doi.org10.7326/M18-2229.

22. Naicker S, Yang C, Hwang S, Liu C, Jha V. The 2019 Coronavirus epidemics and kidney disease. Kidney Int. 2020; https:// doi.org/10.1016/j.kint.2020.03.001.

23. Zhou S, Wang Y, Zhu T, Xia LCT. Features of Coronavirus Disease 2019 (COVID-19) Pneumonia in 62 Patients in Wuhan, China. Am J Roentgenol.2020;214(6):1287-94.1-8.https://doi.org/10. 2214/AJR. 20. 22975.

24. Fisher D, HeymannD.. Q\&A: The novel coronavirus outbreak causing COVID-19. BMC Med. 2020;18(1):57. https://doi.org/ 10.1186/s12916-020-01533-w.

25. National Health Commission of. the People's Republic of China, COVID-19 epidemic situation report. World Health Organization, Coronavirus disease 2019 (COVID-19) Situation Report - 31. 2020.

26. Novel Coronavirus 2019 epidemic and kidneys.Kidney Int https://doi.org 10.1016/j.kint.2020.03.001

Naicker S, Yang CW, Hwang SJ, Jha VThe. Novel Coronavirus 2019 epidemic and kidneys.Kidney Int. 2020;97(5):824-828. https://doi.org 10.1016/j.kint.2020.03.001.

27. Syed-Ahmed M, Narayanan M. Immune dysfunction and risk of infection in chronic kidney disease.Adv Chronic Kidney Dis.2019;26(1):8-15. https://doi.org/ 10.1053/ j.ackd.2019. 01.004.

28. Ferrey AJ, Choi G, Hanna RM, Kalantar-Zadeh KA. Case of Novel Coronavirus Disease 19 in a Chronic Hemodialysis Patient Presenting with Gastroenteritis and Developing Severe Pulmonary Disease.Am J Nephrol.2020;51(5):337-42. https://doi.org/ 10.1159/000507417.

29. BasileC,Combe C, Pizzarelli F, Covic A, Davenport A, Kanbay M. Recommendations for the prevention, mitigation and containment of the emerging SARS-CoV-2 (COVID-19) pandemic in haemodialysiscentres.Nephrol Dial Transplant.2020;35(5):737-41.https://doi.org/ 10.1093/ndt/gfaa069.

\section{Supplementary Files}

This is a list of supplementary files associated with this preprint. Click to download. 
Page 14/14 